\title{
Assemblée Générale du 12 décembre 2009
}

\author{
Élections du Comité Directeur 2010 - 2012
}

\section{P.H. Benamou}

C) Springer-Verlag France 2010

Membres de droit

DIEBOLD Patrice (Nancy), THEMAR NOËL Christine (Paris), DAUM bernard (Nancy)

Membres élus

ABOUKRAT Patrick (Montpellier), BENAMOU Paul Hubert (Paris), BOUYSSET Maurice (Lyon), CORNU Jean Yves (Besançon), DAMIANO Joël (Saint-Mandé), GALOIS Laurent (Nancy), HAMMEL Eric (Pau), HERISSON Christian (Montpellier), JOUET Philippe (Hendaye), MAINARD Didier (Nancy), ROUGEREAU Guillaume (Paris),

UCHAN Jean-Louis (Paris)

Président

$1^{\text {er }}$ Vice Président

$2^{\mathrm{e}}$ Vice Président

Secrétaire Général

Responsable du site Internet

Trésorier

Délégué aux Relations Extérieures

Responsable de la Revue

Relations avec les Sociétés Savantes

Relations avec les Laboratoires

Relations avec les nouveaux Membres

Responsable de l'enseignement
Élection du Bureau 2010 - 2012

Guillaume ROUGEREAU

Maurice BOUYSSET

Eric HAMMEL

Philippe JOUET

Didier MAINARD

Paul-Hubert BENAMOU

\section{Membres cooptés au Bureau}

Christine THEMAR-NOËL

Maurice BOUYSSET

Christine THEMAR-NOËL

Bernard DAUM

Joël DAMIANO

Au cours de cette Assemblée Générale

le Docteur Bernard Daum a été nommé Président d'Honneur de la SFMCP 